\title{
Sylvia Hahn, Historische Migrationsforschung
}

Frankfurt am Main, New York : Campus (Historische Einführungen, 11), 2012, 233 p., 16,90€

\section{Falk Bretschneider}

\section{OpenEdition}

\section{Journals}

Édition électronique

URL : http://journals.openedition.org/ifha/7707

DOI : 10.4000/ifha.7707

ISSN : 2198-8943

\section{Éditeur}

IFRA - Institut franco-allemand (sciences historiques et sociales)

Référence électronique

Falk Bretschneider, "Sylvia Hahn, Historische Migrationsforschung», Revue de I'IFHA [En ligne], Date de recension, mis en ligne le 13 décembre 2013, consulté le 22 septembre 2020. URL : http:// journals.openedition.org/ifha/7707 ; DOI : https://doi.org/10.4000/ifha.7707

Ce document a été généré automatiquement le 22 septembre 2020

(C)IFHA 


\section{Sylvia Hahn, Historische Migrationsforschung}

Frankfurt am Main, New York : Campus (Historische Einführungen, 11), 2012, 233 p., 16,90€

Falk Bretschneider

Sans être un objet totalement nouveau (rappelons par exemple les travaux effectués à l' Institut für Migrationsforschung und interkulturelle Studien à Osnabrück), l'histoire des migrations connaît son heure de gloire, dans l'historiographie en langue allemande, depuis quelques années seulement. Les manuels proposant aux étudiants et chercheurs intéressés un premier contact avec ce champ de recherche ne sont donc pas légion. Chercheuse à l'université de Salzbourg, S. Hahn en publie un qui n'est pas seulement très agréable à lire mais offre également un tour d'horizon assez complet, sans renoncer pour autant à se fixer quelques priorités (les flux migratoires pendant les périodes précédant le temps des États-nations, le rôle des femmes) au détriment de thèmes davantage étudiés (les migrations juives, la traite des noirs, les déplacements forcés pendant et après les grandes guerres du xxe siècle ou l'immigration économique que connaît l'Europe depuis les années 1960).

Neuf chapitres guident le lecteur dans sa découverte: après une brève vue globale, présentant la migration comme faisant partie intégrante de la condition humaine (p.16), des différents phénomènes migratoires qu'a connus l'histoire (européenne) depuis l'Antiquité, le deuxième chapitre propose quelques notions, typologies et approches théoriques essentiels du champ, en retenant les concepts de transculturalité et de transrégionalité comme particulièrement propices à une étude historique des migrations dépassant l'histoire du temps présent. Le chapitre suivant donne un aperçu des différentes formes d'un savoir produit par les autorités laïques et ecclésiastiques, en s'appuyant à partir du xviIIe siècle sur les sciences naissantes, pour mieux comprendre, contrôler et aussi endiguer les flux migratoires (sciences camérales, gute Policey, premières statistiques, etc.), tentatives complétées, dès le début du xxe siècle, par des travaux sociologiques (Tönnies, Weber) puis également historiques (histoire sociale des métiers, débuts d'une histoire des migrations à proprement parler, comme 
par exemple autour de K. Bade à Osnabrück), avant de rejoindre, à l'heure actuelle, les approches d'histoire globale et transnationale. Malgré une production devenue riche, l'auteur constate plusieurs lacunes: les migrations au Moyen Âge et pendant la première modernité, celles qui ont lieu à l'intérieur des petits espaces (on pourrait citer l'exemple des frontières internes, floues et poreuses, du Saint-Empire), la situation spécifique et le rôle particulier des femmes dans les processus migratoires.

Les cinq chapitres suivants essaient de combler ces lacunes. L'auteure donne d'abord quelques éléments sur les nombreux migrants des époques pré-modernes (nobles, ecclésiastiques et soldats, artistes, étudiants, commerçants, artisans et ouvriers, etc.), en insistant notamment sur les cours princières et les villes comme points de cristallisation d'une société en mouvement permanent. Ensuite, S. Hahn s'intéresse aux différentes formes de migration forcée (du bannissement punitif à l'exil pour des raisons religieuses, ethniques ou politiques); aux migrations des domestiques qui formèrent des flux allant de la campagne vers la ville et concernent en outre surtout des jeunes (voire des enfants) et des femmes; à la place particulière qu'ont occupée celles-ci dans l'histoire des migrations (par exemple en suivant leurs maris, produisant ainsi une migration de conjugalité touchant aussi bien princesses et grandes bourgeoises que les couches les plus modestes); aux migrations (surtout économiques) à l'intérieur de l'Europe pendant le xixe siècle; et, dernier chapitre, au xxe siècle qui voit la migration devenir de plus en plus un phénomène global - une évolution initiée par les déplacements massifs de millions de personnes pendant les conflits armés mondiaux, accrue par les contacts entre occupants et occupés et les nombreux mariages transnationaux et renforcée enfin par les immigrations pour des motifs économiques dans la deuxième moitié du siècle.

Écrit d'une plume alerte, soucieux de signaler constamment les sources pouvant être mobilisées pour tel ou tel thème et de recourir à des cas particuliers pour illustrer l'argumentation (des matériaux supplémentaires sont mis à la disposition des lecteurs sur le site de la collection «Historische Einführungen", à l'adresse http:// studium.campus.de/geschichte/historische-einfuehrungen), l'ouvrage de S. Hahn est sans aucun doute une réussite. Une bibliographie sélective bien choisie ainsi que des encadrés donnant par exemple des définitions importantes complètent cette image positive. En revanche, le lecteur français sera peut-être dérouté par certaines citations laissées en anglais. De même, si un hommage est rendu à la recherche anglophone sur plusieurs pages (p. 51-57), les travaux de chercheurs français n'ont droit qu'à cinq lignes (p.66). Enfin, l'ouvrage étant destiné à un public allemand, le regard reste majoritairement fixé sur l'espace germanique - ce qui explique, par exemple, le laconisme des remarques sur les rapports entre colonialisme et migrations. Mais ceci ne saurait ternir l'impression tout à fait favorable que laisse la lecture.

\section{INDEX}

Thèmes : Sozialgeschichte

Index chronologique : Epochenübergreifend 
AUTEUR

FALK BRETSCHNEIDER

École des Hautes Études en Sciences Sociales, Paris 